\title{
Relação entre saúde e saneamento na perspectiva do desenvolvimento
}

\author{
Relationship between health and environmental \\ sanitation in view of the development
}

Léo Heller 1

\begin{abstract}
The present paper discusses the relation between health and public health engineering in the context of social development. Initially we defend the insertion of this concept in the presently used approach, health and environment, recognizing that this new area does not eliminate the relevancy of the health-environment approach, being actually its precursor. We present the concept of public health engineering, its present-day situation in Brasil, as well as the paremeters for the relation healthpublic health engineering. Development indicators from Brazil and other countries are confronted with sanitary indicators demonstrating that in Brazil, taking into consideration the degree of economic development and the extent of offered sanitary services, a better performance of health indicators could be expected. We evaluate the conclusions of epidemiological studies on sanitation and, finally, we discuss the perspectives of the health - public health engineering approach.

Key words Public Health Engineering; Water Supply; Sanitation; Health Indicators; Development
\end{abstract}

Resumo Discute-se a relação entre saúde e saneamento, situando-a no contexto do processo de desenvolvimento social. É defendida inicialmente a inserção dessa relação no atual enfoque saúde e ambiente, reconhecendo que esta nova área não elimina a pertinência da abordagem saúde-saneamento, na verdade sua precursora. Apresenta-se a conceituação de saneamento e sua atual situação no país, além dos marcos conceituais da relação saúde-saneamento. Indicadores de desenvolvimento dos países, enfatizando os brasileiros, são confrontados com indicadores sanitários, mostrando-se que, para o grau de desenvolvimento econômico e a cobertura por serviços de saneamento no Brasil, melhor desempenho dos indicadores de saúde seria esperado. Avaliam-se as assertivas que podem ser extraídas dos estudos epidemiológicos desenvolvidos na área de saneamento e, por fim, discutem-se as perspectivas que se apresentam no campo da relação saúde-saneamento.

Palavras-chave Saneamento; Abastecimento de Água; Esgotamento Sanitário; Indicadores de Saúde; Desenvolvimento

\footnotetext{
1 Departamento de Engenharia Sanitária e Ambiental da UFMG. Av. do Contorno, 842, 7o andar, Belo Horizonte, MG, 30.110-060, Brasil. heller@oraculo.lcc.ufmg.br
} 


\section{Introdução}

Verifica-se atualmente a consolidação do inovador enfoque saúde e ambiente, que encontra na terminologia epidemiologia ambiental seu instrumental metodológico e na expressão saúde ambiental a chave para orientar a organização institucional e para sensibilizar comunidades, técnicos e governos sobre a necessidade de uma abordagem que articule ambas as esferas. Subjacente a essa visão, há a percepção da importância de que saúde e ambiente se aproximem, enquanto conceito e prática. O resultado dessa aproximação para a área da saúde seria a de valorizar o ambiente como fator determinante de agravos à saúde, enquanto que, para a área ambiental, visualizar efeitos das alterações ambientais sobre a saúde humana traria a significativa contribuição de resgatar o impacto sobre a homem nas preocupações do enfoque ambiental, avançando da clássica supervalorização dos impactos sobre o meio físico.

Por outro lado, ao se abordar a relação entre saúde e saneamento, é vital inseri-la no contexto exposto da relação saúde e ambiente. A primeira constatação, nesse aspecto, é de que preocupações sobre a relação saúde-saneamento estiveram, na verdade, na raiz da atual visão saúde-ambiente. Foram quase exclusivamente as questões de saneamento, sobretudo antes da Revolução Industrial, aquelas que historicamente caracterizaram os determinantes ambientais da saúde. E, nesse ponto, os vários marcos que, ao longo da História, denotaram a preocupação da melhoria do ambiente visando à prevenção de problemas com a saúde humana, tiveram no saneamento seu referencial.

Assim, desde dois mil anos antes de Cristo, com o reconhecimento da necessidade de se purificar a água (USEPA, 1990) e de se praticarem hábitos sanitários, até Snow (1990), passando por Hipócrates e pela prática ditada pela teoria miasmática, a trajetória histórica da saúde ambiental foi, até este século, a constatação da relação entre o saneamento e a saúde.

A complexidade da sociedade atual e a decorrente ampliação dos impactos ambientais, tanto sob o ponto de vista de sua natureza quanto de sua abrangência geográfica, em muitos casos atingindo escala planetária, impôs também a expansão da visão dos determinantes ambientais sobre a saúde. Nesse con- texto, mostra-se insuficiente e reducionista a consideração apenas das questões sanitárias, ignorando relevantes problemas ambientais contemporâneos e o risco à saúde a ele associados, a exemplo de fatores das mais diversas naturezas como a poluição atmosférica, o empregos de biocidas na agricultura, o stress urbano e a radiação.

Apesar dessa tendência, há que se ter clara a persistência da importância do papel do saneamento no quadro de saúde, em especial nos países em desenvolvimento. Seria equivocado se substituir a visão de saneamento pela visão ambiental mais ampla, sendo necessário sim se reconhecerem as questões de saneamento como ainda na ordem do dia da saúde ambiental, localizando seu papel, sua pertinência e a aplicabilidade do conceito, identificando sociedades, ocupações, situações e fatores de risco associados.

Nesse particular, deve-se ter claro que a persistência da problemática do saneamento encontra-se fortemente associada ao modelo sócio-econômico praticado e que a população mais vulnerável corresponde justamente àquela excluída dos benefícios do desenvolvimento. Considerando essa premissa, se permanece hegemônico em nível mundial o processo de globalização, suportado por uma visão neo-liberal do desenvolvimento, é legítimo supor que a situação de dependência da economia periférica terá continuidade, acarretando maior exclusão e aprofundamento da pobreza, confirmando a pertinência da manutenção, como contemporânea, das preocupações com a relação saneamento - saúde.

De forma simplificada, pode-se situar que os riscos decorrentes da insalubridade do meio afetam com maior intensidade as populações de menor status sócio-econômico, enquanto que os problemas ambientais originários do desenvolvimento atingem mais homogeneamente a todos os estratos sociais, conforme ilustra-se na Figura 1.

\section{Saneamento}

Para se localizar de forma adequada a presente discussão, é inicialmente necessário que se situe o conceito de saneamento e, daí, sua relação com a saúde. Classicamente, a definição de saneamento baseia-se na formulação da Organização Mundial da Saúde: saneamento constitui o controle de todos os fatores do 
Figura 1

Morbidade/mortalidade por enfermidades devidas à insalubridade do meio e ao desenvolvimento, em função do nível sócio-econômico.

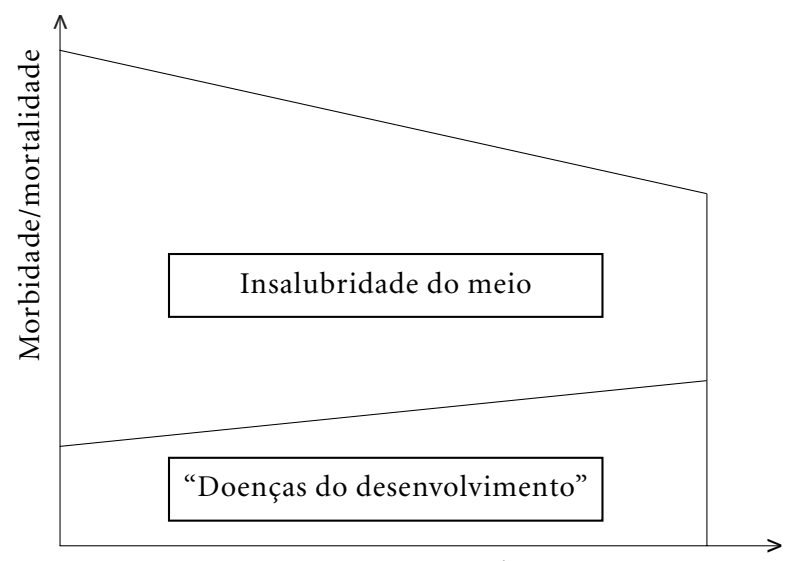

Nível sócio-econômico

meio físico do homem, que exercem ou podem exercer efeitos deletérios sobre seu estado de bem estar físico, mental ou social. Neste conceito, fica clara a articulação do saneamento com o enfoque ambiental, ao situá-lo no campo do controle dos fatores do meio físico, e com a abordagem preventiva de saúde, assumindo que a própria OMS considera o bem estar físico, mental e social como definição de saúde.

Esta conceituação mais geral contribui para a delimitação das ações compreendidas sob a terminologia saneamento, a partir do campo de intervenções a ela associados - fatores do meio físico - e das conseqüências esperadas - prevenção dos efeitos deletérios sobre a saúde. Entretanto, o conceito admite amplas interpretações sobre as ações abrangidas e disciplinas envolvidas. Ao longo da trajetória institucional e avaliando as diversas tentativas de delimitação de seu campo de ação, localizamse desde definições absolutamente estreitas até limites mais amplos para seu significado. No primeiro extremo, o PLANASA - Plano Nacional de Saneamento - em 1971 definiu saneamento básico como apenas as ações de abastecimento de água e esgotamento sanitário. Por outro lado, algumas definições de saneamento ambiental, ao lado das áreas mais clássicas, incluem ações como o saneamento dos alimentos, das habitações e dos locais de trabalho, além da higiene industrial e o controle da poluição atmosférica e sonora. Para efeito de padronização, a tendência predominante no Brasil tem sido a de considerar como integrantes do saneamento as ações de:

- abastecimento de água, caracterizado como o fornecimento às populações de água em quantidade suficiente e com qualidade que a enquadre nos padrões de potabilidade;

- esgotamento sanitário, compreendendo a coleta dos esgotos gerados pelas populações e sua disposição de forma compatível com a capacidade do meio ambiente em assimilá-los; - limpeza pública, incluindo todas as fases de manejo dos resíduos sólidos domésticos, até sua disposição final, compatível com as potencialidades ambientais;

- drenagem pluvial, significando a condução das águas pluviais, de forma a minimizar seus efeitos deletérios sazonais sobre as populações e as propriedades;

- controle de vetores de doenças transmissíveis, especialmente artrópodes e roedores.

Para efeito de apresentação da pertinência da problemática do saneamento, pode-se verificar a carência de cobertura pelos serviços no Brasil, certamente ilustrativo da situação dos países em desenvolvimento.

Segundo a FIBGE (1991), 32\% da população brasileira não é conectada à rede coletiva de água e $68 \%$ não são atendidos por sistema coletivo de esgotos. Além disso, parcela considerável da população abastecida por água recebe água intermitentemente e com qualidade duvidosa. E quase a totalidade dos esgotos coletados é lançado nos cursos d'água sem receber qualquer tipo de tratamento.

Em relação à limpeza pública, segundo a mesma fonte, $44 \%$ da população brasileira não é atendida por serviços de coleta.

\section{Relação saúde-saneamento: marcos conceituais}

Alguns modelos têm sido propostos para explicar a relação entre ações de saneamento e a saúde, enfocando distintos ângulos da cadeia causal. Entretanto, as formulações têm privilegiado a compreensão sanitária do abastecimento de água e do esgotamento sanitário, em detrimento das outras ações de saneamento. Além disso, os modelos não guardam uma mesma lógica em sua formulação, encontrando-se desde modelagens basicamente biologi- 
cistas até explicações que privilegiam uma visão mais sistêmica, com ênfase para os determinantes sociais. Em todos os casos, porém, aspectos da relação saneamento-saúde procuram ser elucidados.

Em relação aos modelos que associam o abastecimento de água e o esgotamento sanitário com a saúde, vários autores procuram dar conta da complexidade dessa relação, explicando a influência sobre indicadores específicos, como a diarréia, ou sobre medidas mais abrangentes de saúde, como a mortalidade infantil ou a expectativa de vida. Além disso, a discussão sobre efeitos da intervenção a curto e a longo prazos são também encontrados. Nesse último aspecto, Briscoe (1985) postula que, se a curto prazo o efeito mensurável do abastecimento de água e do esgotamento sanitário pode parecer reduzido, pela reposta não linear da intervenção, a longo prazo seu efeito sobre a saúde é substancialmente superior ao de intervenções médicas. Baseado em uma simulação de dados demográficos de Lyon (França), entre 1816 e 1905, prevê que as intervenções ambientais podem prevenir cerca de quatro vezes mais mortes e elevar a expectativa de vida sete vezes mais, que as intervenções de natureza biomédica. O mesmo autor (Briscoe, 1987) afirma que tal comportamento sugere um efeito multiplicador dos programas de abastecimento de água e esgotamento sanitário.

Em outra formulação, Cvjetanovic (1986) caracteriza como estreitos os modelos que relacionam as ações de saneamento com um grupo definido de doenças, como as enfermidades diarréicas. Afirma que tal enfoque ignora o caráter amplo da definição de saúde formulada pela Organização Mundial da Saúde, ao avaliar impactos sobre doenças e não sobre a saúde propriamente. Reconhece, entretanto, os obstáculos metodológicos para uma abordagem holística, que privilegie sobretudo os fatores sócio-econômicos. Esquematicamente, a Figura 2 ilustra o modelo proposto pelo autor, no qual se prevê que ações de abastecimento de água e de esgotamento sanitário proporcionam benefícios gerais sobre a saúde da população segundo duas vias: através de efeito direto e através de efeitos indiretos, resultantes primordialmente do desenvolvimento da localidade atendida. Observe-se que, embora pleiteando uma explicação causal mais sistêmica, o modelo de Cvjetanovic não inclui o papel dos determinantes sociais.
Por outro lado, no campo da limpeza pública localizam-se algumas referências, que contribuem para iniciar a formulação de um modelo causal, ainda a ser construído e validado. Najm (s.d.) propõe um esquema das vias de contato lixo-homem (Figura 3) que, sinteticamente, explica as trajetórias através das quais pode ocorrer transmissão de doenças oriundas da disposição inadequada dos resíduos sólidos urbanos. Note-se que, dada a diversidade de vias e, especialmente, a ação dos vetores - biológicos e mecânicos - o raio de influência e os agravos sobre a saúde mostramse de difícil identificação.

A Figura 4 propõe um modelo esquemático, relacionando a solução para as diversas etapas do manejo dos resíduos sólidos domésticos com o risco à saúde.

Alguns modelos de caráter geral também são localizados, a exemplo de estudo desenvolvido no Sri-Lanka (Waxler et al., 1985), que trabalhou um modelo causal da mortalidade infantil, composto por uma teia de determinantes, na qual atuam preditores culturais, sócio-econômicos e médicos (Figura 5). Notase que a situação de saneamento, representada pelo atendimento por fossa, localiza-se em uma etapa mais terminal do ciclo de relações, em um sentido sendo determinada por fatores econômicos, culturais e educacionais e em outro, determinando a mortalidade infantil. $\mathrm{Na}$ conclusão desse estudo, explica-se a mortalidade infantil em Sri-Lanka da seguinte forma:

"O status dos grupos minoritários resulta em pobreza, o que impede a família de possuir instalações sanitárias seguras, causando morte infantil. A mortalidade infantil em SriLanka não é, portanto, simplesmente um problema médico, para ser assumido pelos programas de saúde pública, nem tampouco é um problema econômico, que possa ser resolvido pela criação de empregos, mas é melhor que seja encarada como um problema da estrutura de toda a sociedade."

$\mathrm{Na}$ mesma linha, estudo epidemiológico realizado na sede urbana de Betim-MG (Heller, 1997a), cidade de porte médio com população de aproximadamente 160.000 habitantes, permite inferir o marco causal da diarréia em crianças de até cinco anos, a partir de determinantes sócio-econômicos e relacionados ao saneamento. A Figura 6 exibe o modelo. 
Figura 2

Efeitos diretos e indiretos do abastecimento de água e do esgotamento sanitário sobre a saúde: esquema conceitual.

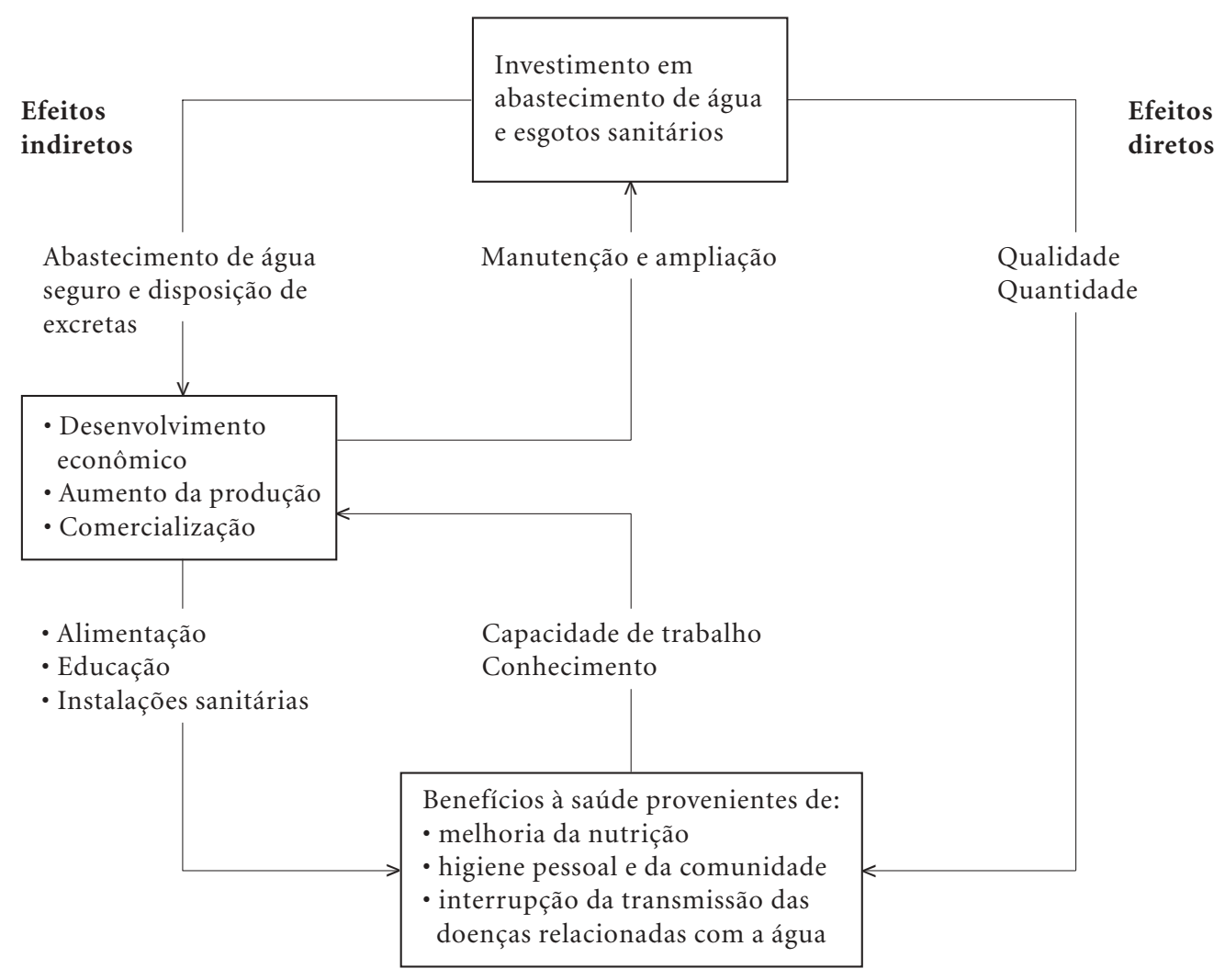

Fonte: Cvjetanovic (1986).

\section{A relação com o desenvolvimento}

A relação entre saneamento e desenvolvimento é bastante clara. Em geral, países com mais elevado grau de desenvolvimento apresentam menores carências de atendimento de suas populações por serviços de saneamento. Ao mesmo tempo, países com melhores coberturas por saneamento têm populações mais saudáveis, o que por si só constitui um indicador de nível de desenvolvimento.

O PNUD - Programa das Nações Unidas para o Desenvolvimento - vem levantando desde 1990 o IDH - Índice de Desenvolvimento Humano, para os diferentes países. Este índice, cujo valor varia entre zero e um, compõe-se de três fatores: expectativa de vida, conhecimento (alfabetização e instrução) e padrão de vida (produto doméstico bruto per capita).
Ao se compararem os indicadores de desenvolvimento do Brasil com o conjunto dos países, alguns aspectos chamam a atenção. A Figura 7 mostra a relação entre o valor do IDH na escala de todos os países e a expectativa de vida, um dos componentes do índice. Observase que o ponto correspondente à posição brasileira encontra-se abaixo da linha de tendência, demonstrando que a expectativa de vida no Brasil é cerca de 5,3 anos inferior ao esperado pelo seu IDH, sugerindo um descompasso entre crescimento econômico e qualidade de vida.

Por outro lado, relacionando-se o produto doméstico bruto per capita - um indicador da renda média da população - e a mortalidade infantil, conforme Figura 8, observa-se novamente que o par de valores característico do Brasil localiza-se sob a curva de tendência. Isto pode ter significado similar à interpretação 
Figura 3

Esquemas das vias de contato homem-lixo.

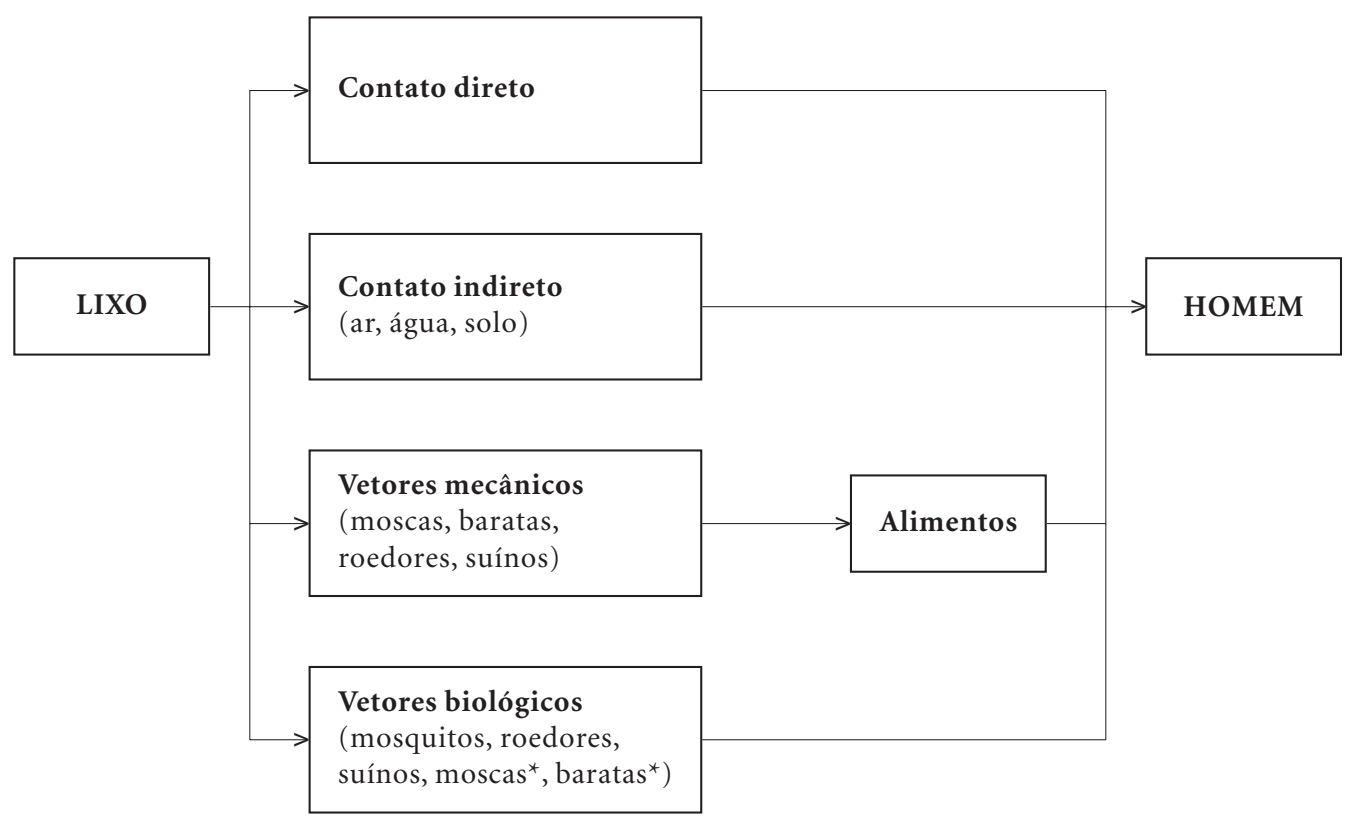

* introduzido pelo autor.

Fonte: NAJM (s. d.).

anterior, ou seja, caso o padrão de desenvolvimento brasileiro tivesse uma natureza próxima ao da média mundial, a mortalidade infantil média da população poderia ser de 33,7 óbitos por 1.000 crianças nascidas vivas, 10,3 aquém dos atuais 44 .

Finalmente, corroborando a análise anterior sobre o padrão de desenvolvimento brasileiro, as Figuras 9 e 10 sugerem que, com os níveis de cobertura por abastecimento de água e esgotamento sanitário do Brasil, melhores condições de saúde infantil poderiam ser verificadas, reduzindo a taxa de mortalidade infantil para cerca de 16 ou 22 óbitos por 1.000 crianças nascidas vivas, respectivamente.

É evidente que a otimização do impacto das intervenções em saneamento sobre a saúde da população está também condicionada a transformações estruturais e institucionais. Há um crônico distanciamento entre as políticas de saneamento e de saúde no Brasil. Por um lado, a prática e os planejamentos do setor de saneamento não valorizam a relação com a saúde, havendo inclusive deficiências na formação dos profissionais. E, por outro, as políticas de saúde do país permanecem privilegiando a ótica curativa, verificando-se poderosos óbices para a integração com essa visão e o reconhecimento na prática do papel preventivo das ações de saneamento.

Estas comparações entre indicadores de desenvolvimento e o quadro de saúde brasileiros são úteis no sentido de demonstrar a possibilidade de, com políticas públicas com real compromisso social, se obterem significativos avanços na qualidade de vida da população. Fato certamente associado à ausência de um maior impacto do crescimento econômico e também das ações de saneamento sobre a saúde da população é o quadro de desigualdade social, que retém a ampliação dos benefícios. O UNDP (1994) mostra que o Brasil é o segundo país do mundo em concentração de renda, após Botsuana: a renda dos $40 \%$ mais pobres corresponde a apenas $7 \%$ da renda nacional e os $20 \%$ mais ricos têm 32,1 vezes mais renda que os $20 \%$ mais pobres. $\mathrm{Na}$ publicação de 1997, o PNUD indica que o coeficiente de Gini brasileiro é o maior - 63,4\% dentre 64 países. 
Figura 4

Limpeza pública e saúde - modelo causal.

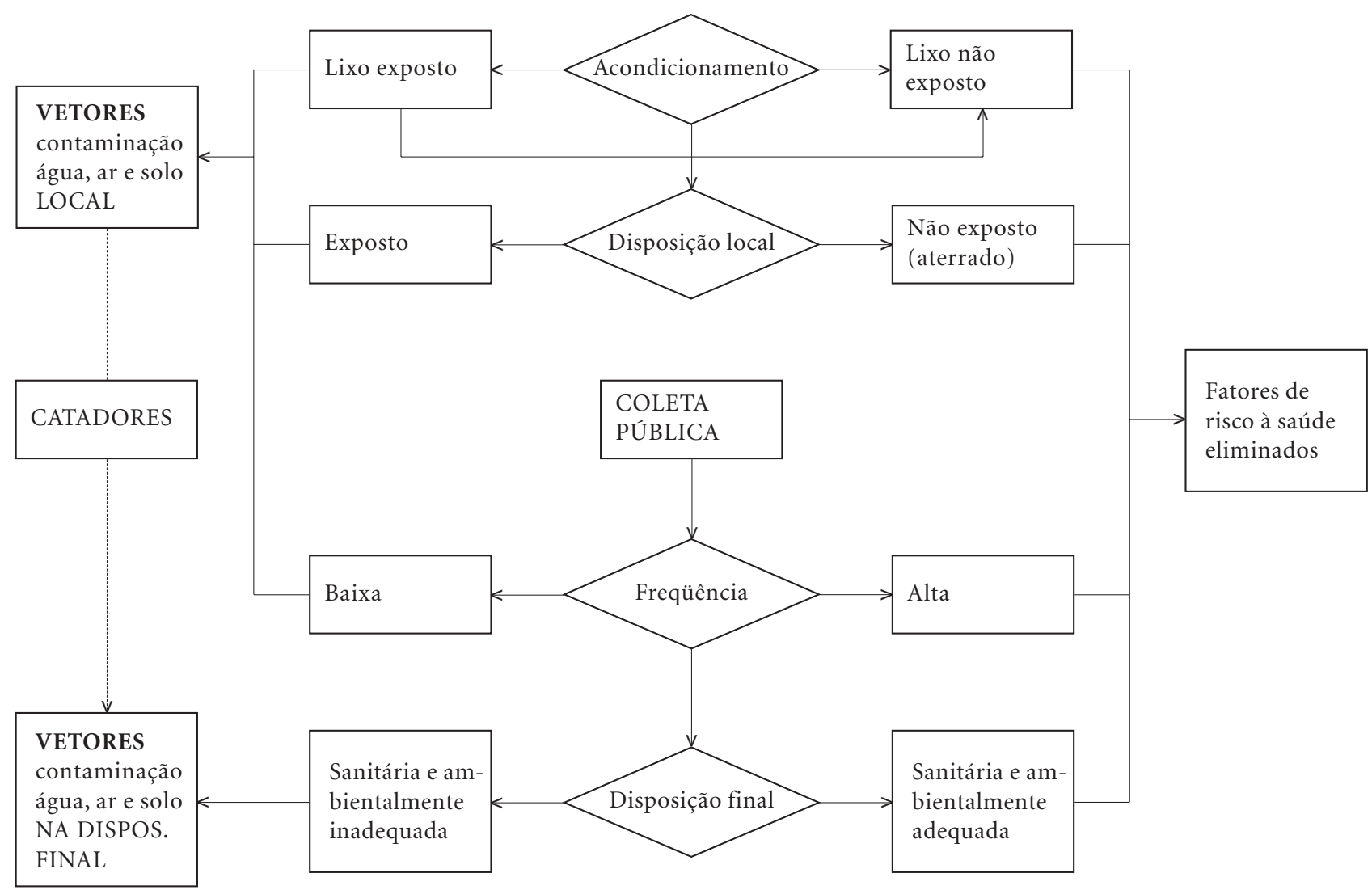

\section{Relação saúde-saneamento: assertivas em construção}

Diversos estudos epidemiológicos, investigando a relação entre saúde e saneamento, já foram desenvolvidos, contemplando diferentes indicadores de saúde, diferentes ações de saneamento e diferentes realidades sócio-econômicas e geográficas.

Desses estudos, observa-se uma maior concentração de interesses na áreas tradicionais do saneamento. Assim, dentre 256 estudos publicados, 198 deles investigaram o abastecimento de água, 104 o esgotamento sanitário, enquanto que limpeza pública, hábitos higiênicos e outras exposições foram analisados em apenas 67 trabalhos. Há também uma maior incidência de estudos voltados para as realidades asiática (29\%) e africana (27\%), localizando-se apenas 26 dos 256 estudos tendo co- mo objeto populações da América do Sul (Heller, 1997a).

Na maioria dos estudos publicados, vem sendo relatada uma associação positiva entre saneamento e o indicador de saúde analisado. Entretanto, ainda não se pode afirmar já existir uma avaliação abrangente o suficiente para afirmar especificidades dessa relação. Localizam-se as seguintes lacunas:

- distinção das populações sob risco, para diversas situações de ausência de condições adequadas de saneamento;

- efeito das intervenções sobre os diversos agravos à saúde e indicadores;

- efeito de cada intervenção em saneamento isoladamente;

- efeito conjugado das intervenções, inclusive modificação de efeito de uma intervenção sobre outras;

- quantificação dos riscos. 
Figura 5

Marco causal da mortalidade infantil no Sri-Lanka.

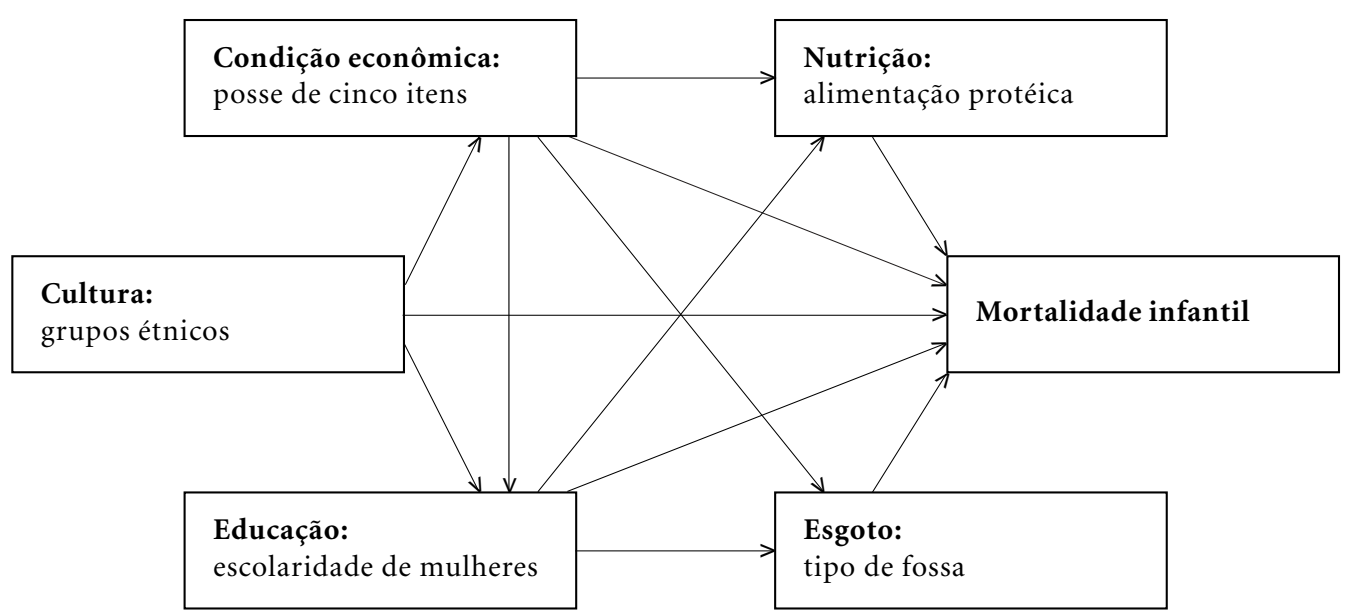

Fonte: adaptado de Waxler et al. (1985).

\section{Figura 6}

Marco causal da diarréia em Betim, MG.

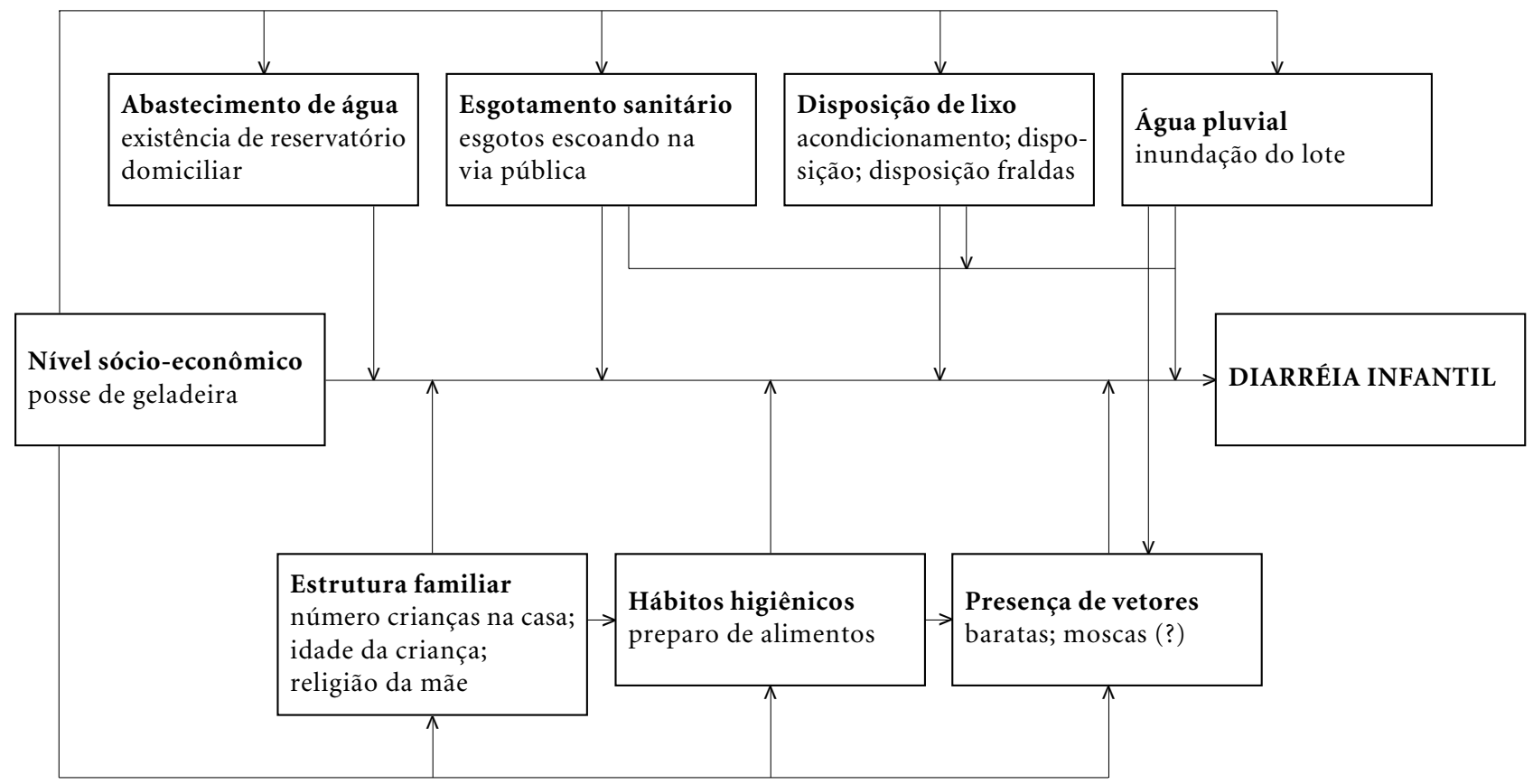

Fonte: Heller (1997a). 
Figura 7

Relação entre IDH e expectativa de vida dos países (valores de 1994).

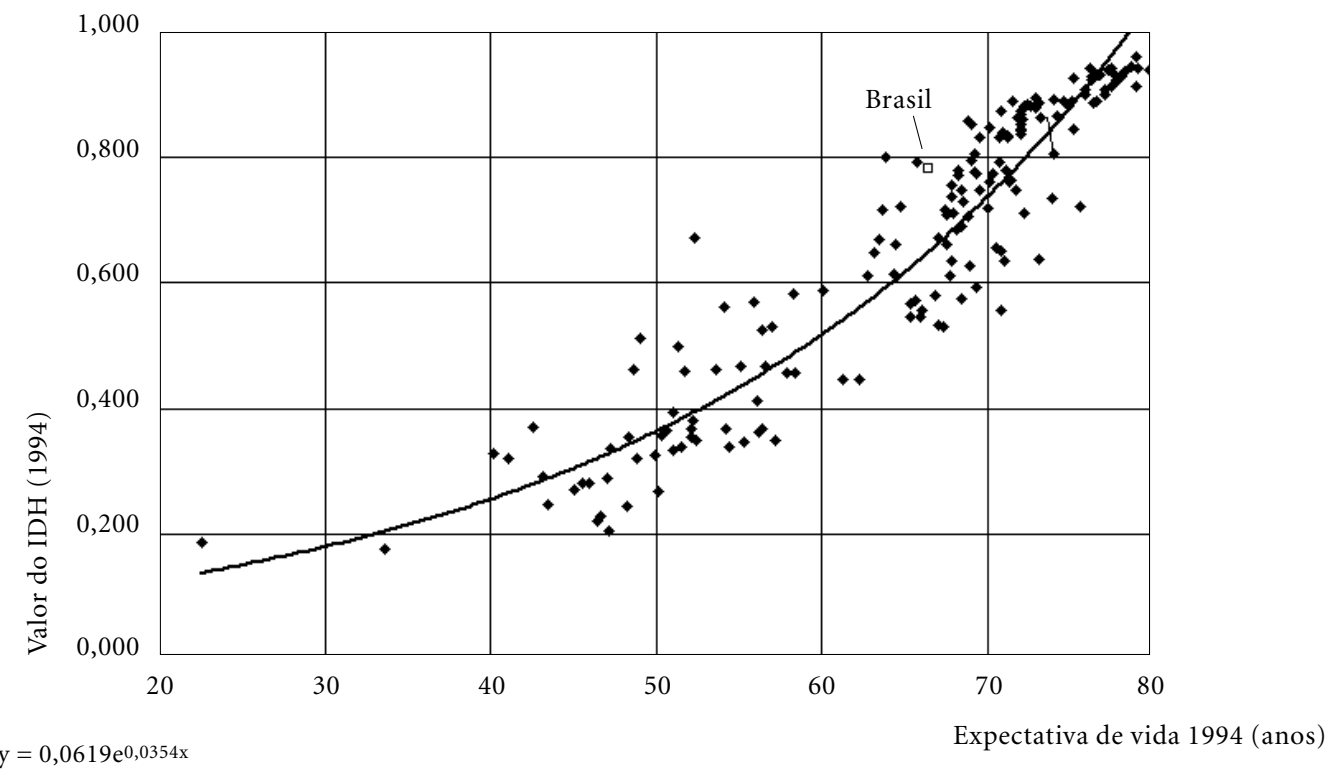

$\mathrm{y}=0,0619 \mathrm{e}^{0,0354 \mathrm{x}}$

Expectativa de vida 1994 (anos)

\section{$\mathrm{R}^{2}=0,8736$}

Fonte: PNUD (1994).

\section{Figura 8}

Relação entre produto doméstico bruto per capita (1994) e mortalidade infantil (1995) dos países.

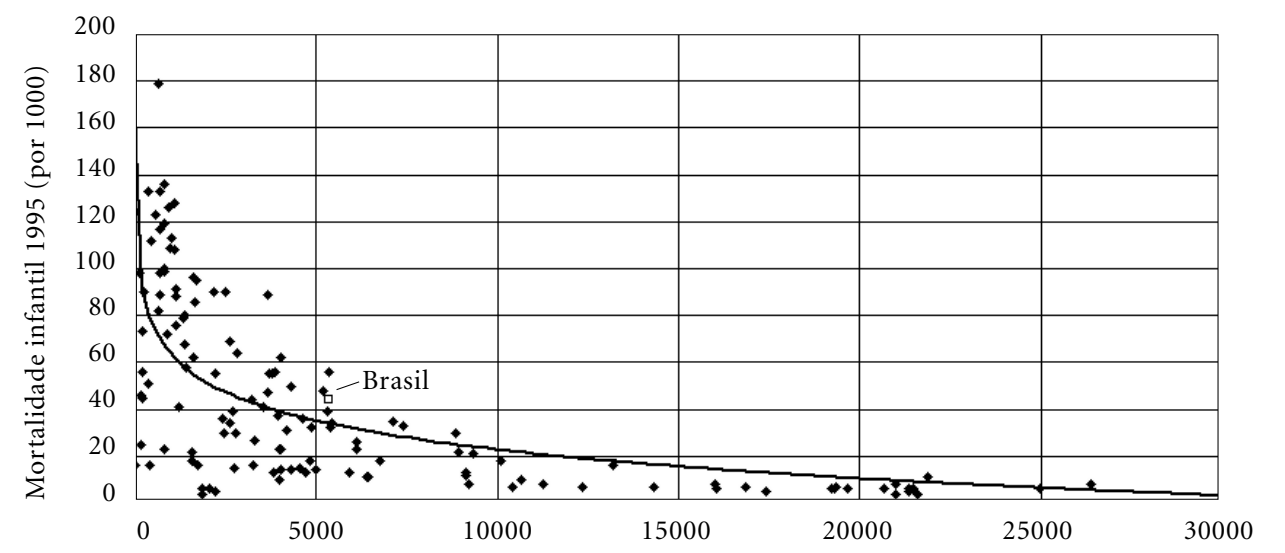

$\mathrm{y}=17,756 \operatorname{Ln}(\mathrm{x})+186$

Produto doméstico bruto per capita (1994)

$$
\mathrm{R}^{2}=0,4136
$$

Fonte: PNUD (1997). 
Figura 9

Relação entre cobertura por abastecimento de água (1994-95) e mortalidade infantil (1995) dos países.

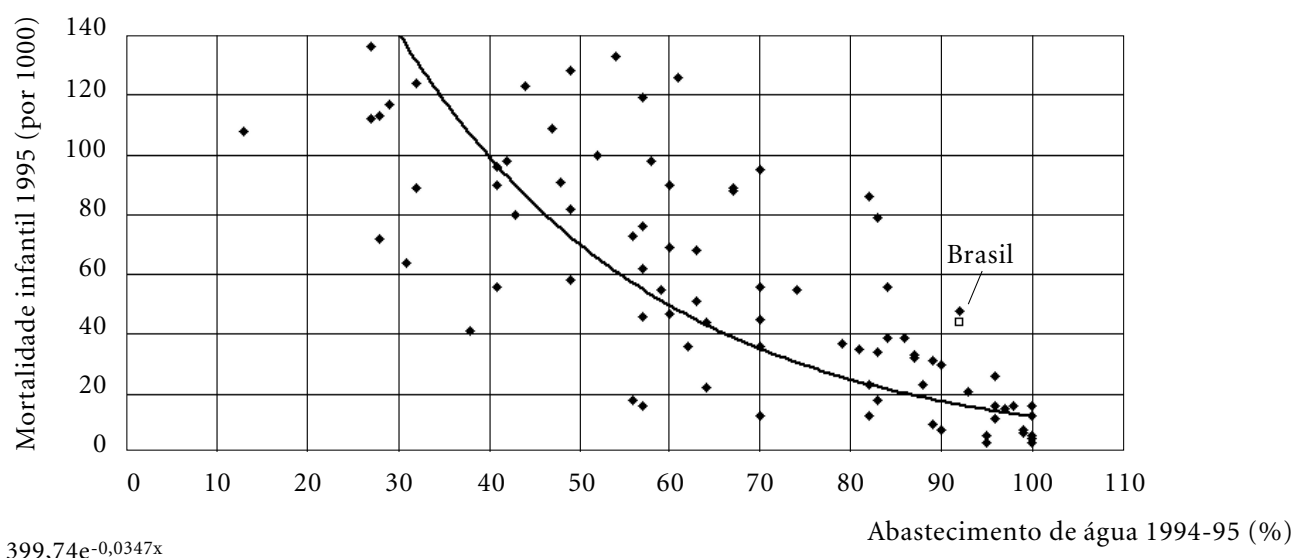

$399,74 \mathrm{e}^{-0,0347 x}$

$\mathrm{R}^{2}=0,6284$

Fonte: PNUD (1997)

\section{Figura 10}

Relação entre cobertura por esgotamento sanitário (1994-95) e mortalidade infantil (1995) dos países.

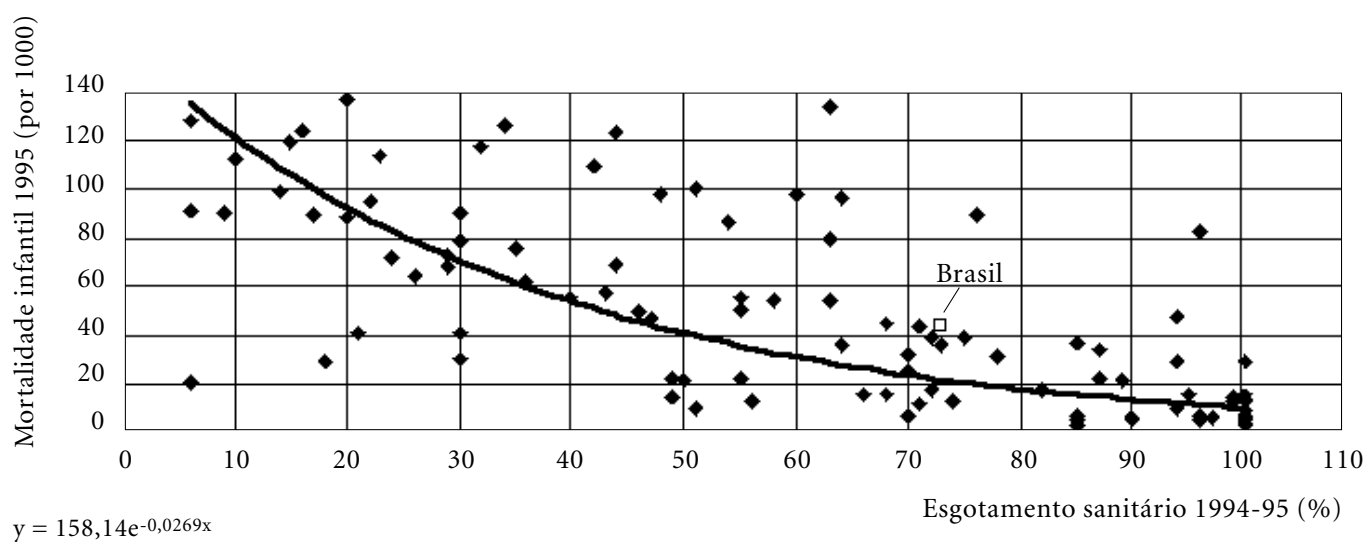

$\mathrm{y}=158,14 \mathrm{e}^{-0,0269 x}$

$\mathrm{R}^{2}=0,5787$

Fonte: PNUD (1997).

Em relação à quantificação dos riscos, importante contribuição é o trabalho de Esrey et al. (1991), que verificaram a redução de enfermidades selecionadas e particularmente da diarréia, a partir da consulta a 144 estudos (Tabelas 1 e 2).

Tais agregações quantitativas esbarram por vezes em elevada dispersão dos resultados, o que é presumível, dada a diversidade de realidades estudadas. Contudo, ainda assim são valiosas, na medida em que configuram valores medianos, os quais, mesmo imprecisos, contribuem para uma visão inicial.

Em relação às assertivas passíveis de serem extraídas dos estudos realizados, Roberts (1997) propõe que as seguintes conclusões possam ser estabelecidas: 
Tabela 1

Redução percentual na morbidade por diarréia, atribuída a melhorias no abastecimento de água ou no esgotamento sanitário.

\begin{tabular}{lcccc}
\hline Intervenção & \multicolumn{2}{c}{ Todos os estudos } \\
& $\mathrm{n}^{1}$ & $\begin{array}{c}\text { Redução } \\
\text { mediana (\%) }\end{array}$ & $\begin{array}{c}\text { Estudos mais rigorosos } \\
\mathrm{n}^{1}\end{array}$ & $\begin{array}{c}\text { Redução } \\
\text { mediana (\%) }\end{array}$ \\
\hline Abastecim. de água e esgotam. sanitário & $7 / 11$ & 20 & $2 / 3$ & 30 \\
Esgotamento sanitário & $11 / 30$ & 22 & $5 / 18$ & 36 \\
Qualidade e quantidade de água & $22 / 43$ & 16 & $2 / 22$ & 17 \\
Qualidade da água & $7 / 16$ & 17 & $4 / 7$ & 15 \\
Quantidade de água & $7 / 15$ & 27 & $5 / 10$ & 20 \\
\hline
\end{tabular}

1 Número de estudos para os quais é possível a determinação da redução da morbidade/número total de estudos. Fonte: Esrey et al. (1991).

Tabela 2

Redução percentual na morbidade e mortalidade por doenças selecionadas, atribuída a melhorias no abastecimento de água e no esgotamento sanitário.

\begin{tabular}{|c|c|c|c|c|}
\hline \multirow[t]{2}{*}{ Intervenção } & \multicolumn{2}{|c|}{ Todos os estudos } & \multicolumn{2}{|c|}{ Estudos mais rigorosos } \\
\hline & $\mathrm{n}$ & $\begin{array}{l}\text { Redução } \\
\text { mediana }^{1}(\%)\end{array}$ & $\mathrm{n}$ & $\begin{array}{l}\text { Redução } \\
\text { mediana }^{1}(\%)\end{array}$ \\
\hline Ascaridíase & 11 & $28(0-83)$ & 4 & $29(15-83)$ \\
\hline \multicolumn{5}{|l|}{ Doenças diarréicas } \\
\hline Morbidade & 49 & $22(0-100)$ & 19 & $26(0-68)$ \\
\hline Mortalidade & 3 & $65(43-79)$ & - & - \\
\hline Ancilostomíase & 9 & $4(0-100)$ & 1 & $4(-)$ \\
\hline Esquistossomose & 4 & $73(59-87)$ & 3 & $77(59-77)$ \\
\hline Tracoma & 13 & $50(0-91)$ & 7 & $27(0-79)$ \\
\hline Mortalidade infantil & 9 & $60(0-82)$ & 6 & $55(20-82)$ \\
\hline
\end{tabular}

1 Os números entre parênteses correspondem à faixa de variação.

Fonte: Esrey et al. (1991).

1) O acesso a instalações para a disposição de excretas é geralmente mais protetor contra a diarréia que o acesso a maior quantidade de água ou a água mais limpa.

2) Quantidades adequadas de água parece ser mais benéfico na redução de taxas de diarréia que o acesso a água de melhor qualidade.

3) Melhoria na qualidade da água é relativamente vulnerável a ter seus benefícios anulados por outros fatores comportamentais ou ambientais.

De fato, as três questões levantadas têm sido objeto de discussão nos estudos epidemiológicos relacionados ao saneamento e alguns deles deixam antever as conclusões extraídas por Roberts. É importante, no entanto, relativizar tais conclusões, evitando algum risco de generalização e de direcionamento das políticas públicas com base nesses princípios.

Em primeiro lugar, para a compreensão do maior impacto positivo da disposição de excretas em relação ao abastecimento de água ou da superioridade da melhoria da quantidade de água sobre a qualidade (conclusões 1 e 2), devem ser bem situadas as realidades que ensejaram tais afirmativas. Na verdade, a maior parte dos estudos envolvendo a disposição de excretas confronta a implantação de sistemas mais simplificados, em geral estáticos como a fossa seca, com a ausência de qualquer solução para essa disposição. Da mesma forma, em geral a solução para o abastecimento de água considerada consiste de chafarizes ou implantação de bombas manuais em poços rasos, implantado em comunidades que mantinham a 
prática de se abastecer em fontes distantes, transportando manualmente a água. Tais estudos em sua maioria foram desenvolvidos para áreas rurais africanas ou asiáticas, em alguns casos campos de refugiados. Portanto, realidades muito distintas de zonas urbanas, como as encontradas no Brasil.

Em relação à terceira conclusão, estudos brasileiros vêm também confirmando a maior importância das prática higiênicas e da educação sanitária sobre as intervenções físicas no campo do saneamento (Heller, 1997b). Parece correto afirmar, como o faz Roberts, que medidas de saneamento, sobretudo como a melhoria da qualidade da água, pode ter seus efeitos sobre a saúde minimizados ou até mesmo anulados por fatores de ordem comportamental ou ambiental, como a presença de contaminação no meio.

\section{Perspectivas}

Tem sido freqüente a denúncia sobre o descompasso entre as ações de saúde e as ambientais e, mais particularmente, entre as ações de saúde e as de saneamento. Parece que, sobre

\section{Referências}

Briscoe J 1987. Abastecimiento de agua y servicios de saneamiento; su funcion en la revolucion de la supervivencia infantil. Boletin de la Oficina Sanitaria Panamericana 103 (4): 325-339.

Briscoe J 1985. Evaluating water supply and other health programs: short-run vs long-run mortality effects. Public Health 99 (3): 142-145.

Cvjetanovic B 1986. Health effects and impact of water supply and sanitation. World Health Statistics Quarterly 39: 105-117.

Esrey SA, Potash JB, Roberts L \& Shiff C 1991. Effects of improved water supply and sanitation on ascariasis, diarrhoea, dracunculiasis, hookworm infection, schistosomiasis, and trachoma. Bulletin of the World Health Organization 59 (5): 609-621.

FIBGE - Fundação Instituto Brasileiro de Geografia E Estatística 1991. Censo Demográfico 1991. Resultados do Universo Relativo às Características da População e dos Domicílios. FIBGE, Rio de Janeiro.

Heller L 1997a. Saneamento e Saúde. Organização PanAmericana da Saúde, Brasília.

Heller L 1997b. Pesquisa em saúde e saneamento no DESA/UFMG: base conceitual e projetos desenvolvidos. In L Heller, LRS Moraes, TCN Monteiro, MJ Salles, LM Almeida \& J Câncio (orgs.) - Saneamento isto, uma tendência vem se estabelecendo no sentido de se reconhecer a importância dessa aproximação, envolvendo dois distintos níveis, não excludentes.

Em um primeiro nível, impõe-se uma aproximação conceitual, baseada em análises científicas dessa relação. Entende-se que, para tanto, o aprofundamento da compreensão da referida relação pode ter um importante efeito sobre a prática de ambas as áreas. E, claramente, lacunas nessa compreensão são identificadas, tanto sob o ponto de vista quantitativo da associação entre exposição e estado de saúde, quanto sob aspectos específicos das intervenções de saneamento e seus efeitos específicos sobre distintos agravos à saúde.

O segundo nível é justamente aquele operacional e institucional, referenciado na rotina das respectivas áreas. Nesse ponto, a hegemonia assistencial e curativa da área de saúde necessita ser substituída por uma lógica onde prevaleça a visão preventivista, com ênfase para a ação do ambiente. Da mesma forma, a área de saneamento carece de aproximação com a perspectiva de saúde pública, visualizando seus fins e não os meios para atingi-los e, assim, ampliando a eficácia de suas ações. e Saúde nos Países em Desenvolvimento. CC\&P Editores, Rio de Janeiro.

PNUD - Programa das Nações Unidas para o Desenvolvimento 1997. Relatório do Desenvolvimento Humano. PNUD, Brasília.

Roberts L 1997. Conclusions from the literature: an overview of epidemiological associations between water, sanitation and disease. In L Heller, LRS Moraes, TCN Monteiro, MJ Salles, LM Almeida \& J Câncio (orgs.) - Saneamento e Saúde nos Países em Desenvolvimento. CC\&P Editores, Rio de Janeiro.

Snow J 1990. Sobre a Maneira de Transmissão do Cólera. 2a ed. HUCITEC-ABRASCO, São Paulo.

USEPA - United States Environmental Protection Agency 1990. Environmental Pollution Control Alternatives: Dinking Water Treatment for Small Communities. USEPA, Cincinnati.

UNDP - United Nations Development Programme 1994. Human Development Report 1994. Oxford, New York.

Waxler NE, Morrison BM, Sirisena WM \& Pinnaduwage S 1985. Infant mortality in Sri Lankan households: a causal model. Social Science \& Medicine 20 (4): 381-392. 